\title{
Development of a New Flap for a Light Utility Transport Aircraft
}

\author{
B. Eggleston $*$ W.D. McKinney $*$ J. Banaszek $*$ N.S. Choi $*$ G. Krolikowski $*$ F. Lebrun $*$ J. Thompson $*$ D.W. Zingg \\ ** M. Nemec ** S. De Rango **
}

\begin{abstract}
The Bush Hawk XP, which is produced by Found Aircraft of Canada, is a small, piston-engined utility transport aircraft suitable for bushplane operations. The original version was made in the 1960s, and it uses a sealed, plain hinged flap. In the latest production version the gross weight is increased substantially, necessitating an improved flap design to achieve better airfield distances and climb performance.

This paper describes the aerodynamic design and development of a new single-slotted flap for the Bush Hawk. The flap shape and locations when deflected were optimized using modern CFD methods, and wind tunnel tests were bypassed. The features of the flap aerodynamic design, the aircraft structure, and the flap drive systems are described. Flight test results are presented for the Bush Hawk with the new flap; they show outstanding performance in its category.
\end{abstract}

continued on page 234

\section{INTRODUCTION}

The Bush Hawk XP, which is made by Found Aircraft of Canada, is a rugged, five-place, piston-engined aircraft suitable for bushplane type of operations, see Figure 1. The original FBA-2C version was produced in the 1960s. It used a plain hinged flap along with a $250 \mathrm{hp}(1 \mathrm{hp}=746 \mathrm{~W})$ Lycoming 0 540 piston engine for power. Twenty-seven were manufactured, and examples of the original aircraft are still flying regularly in

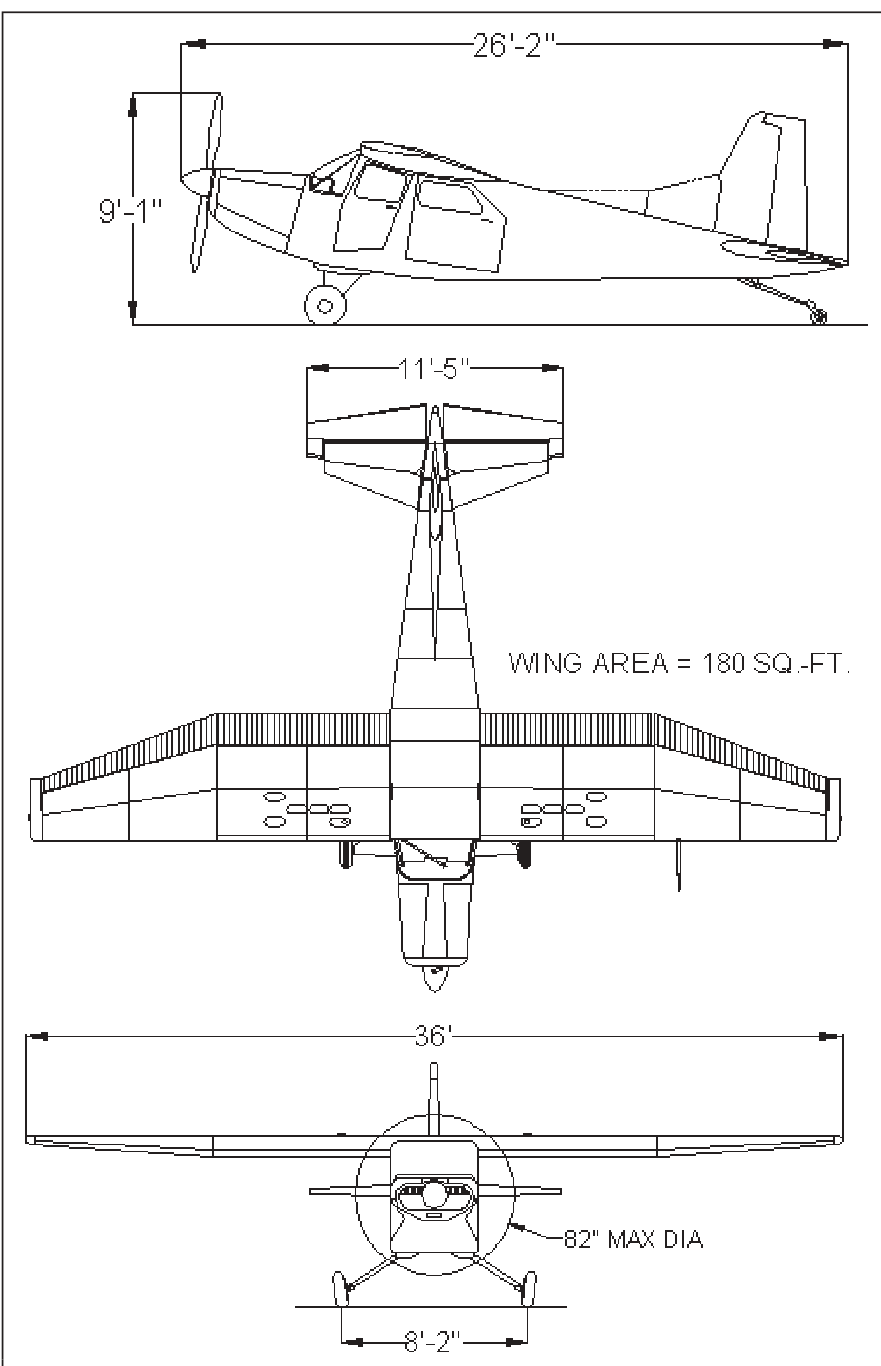

Figure 1. Three views of Bush Hawk XP, FBA-2C1 300 hp landplane with slotted flap.

Received 9 September 2002. 


\section{suite de la page 233}

\section{RÉSUMÉ}

Le Bush Hawk XP, fabriqué par Found Aircraft Canada, est un avion utilitaire léger à moteur à pistons conçu pour le vol de brousse. La version originale de cet appareil fut fabriquée dans les années soixantes et est équipée de volets simples. La version présentement en production dispose d'une masse maximale en charge grandement accrue, ce qui nécessita le développement de volets hypersustentateurs plus évolués pour permettre d'améliorer les performances de décollage, d'atterrissage et de montée.

Cet article décrit le processus de conception aérodynamique et le développement d'un nouveau volet à fente pour le Bush Hawk. La forme et la position des volets lorsque déployés ont été optimizées à l'aide de techniques modernes de mécanique des fluides assistée par ordinateur (CFD) et les tests en soufflerie ont été éliminés. Les caractéristiques du nouveau volet, de la structure de l'aéronef et du mécanisme de déploiement sont exposées. Les résultats des essais en vol sont présentés pour le Bush Hawk avec le nouveau volet et démontrent une performance exceptionnelle dans sa catégorie.

bush operations in Canada and Alaska, which is a testament to the durability of the airframe.

The aircraft is now back in production but substantially redesigned to meet recent structural requirements. The first new version produced retained the plain flaps, but the engine power was increased to $260 \mathrm{hp}$ and the maximum gross weight was increased to $3200 \mathrm{lb}(1 \mathrm{lb}=0.454 \mathrm{~kg})$ to improve payload range. After a few deliveries this version was superseded.

The version now in production is designated the Bush Hawk $\mathrm{XP}$, and relative to the original 1960s aircraft it increases the gross weight by about $25 \%$ to $3500 \mathrm{lb}$ and engine power by 20\% using a $300 \mathrm{hp}$ Lycoming IO-540 engine. An improved flap was needed to obtain gains in takeoff and climb performance that are of particular importance for floatplane operations. Accordingly, a new chord extending, single-slotted flap was designed using modern CFD methods.

This paper describes the design features and development of the new flap and presents flight test results. Obtaining the certification to Transport Canada Chapter 523 and the equivalent US FAR 23 for the XP was a formidable challenge for the small team at Found Aircraft. All aspects of design and testing were handled in house, including the complete structure, powerplant installation, landing gear, flight test, and the airfield noise qualification.

\section{Flap Aerodynamic Design}

The resources available to a small, start-up company are very limited, so an aerodynamic development program involving wind tunnel testing was not practical from either time or cost considerations. Therefore, it was decided to risk undertaking the aerodynamic design of the flap using modern CFD methods and then proceed directly to the test aircraft to prove that the performance and handling qualities were acceptable.

The aerodynamic design of the flap was done cooperatively by Found and research staff at the University of Toronto Institute of Aerospace Studies (UTIAS). The CFD methods used included a UTIAS-developed 2-D Navier-Stokes code called Tornado (Nelson et al., 1993; Godin et al., 1997) and the 2-D viscous Euler code MSES by Drela and Giles (1987). The aerodynamic estimates to be given later were made at a chordbased Reynolds number of $3.5 \times 10^{6}$ and a Mach number of 0.15 . The boundary layer transition was fixed at $3 \%$ on the airfoil and flap upper surfaces and at $5 \%$ on their lower surfaces.

The aerodynamic configurations of the new slotted flap and the original flap are compared in Figure 2. The new flap is $30 \%$ of the wing chord, and the shroud lip is at $82 \%$ of the chord. The shapes of the new flap, the wing lower shroud, and the gaps and overlaps were optimized on the computer for lift:drag ratio and high maximum lift coefficients at deflections up to $35^{\circ}$ as could be used for landing. The resulting locations were made suitable for either four bar linkages or slotted tracks to support the flaps. In fact the aircraft needs to use only $30^{\circ}$ of flap for landing, as the approach rate of sink achieved is already above $1000 \mathrm{ft} / \mathrm{min}$. This reduced the travel required and allowed the tracks to be shortened accordingly.

The inner flapped part of the Bush Hawk wing uses a NACA 23016 section, and the lift-curve results predicted using the Tornado and MSES codes are shown in Figure 3. The Tornado

FOUND BUSH-HAWK PLAIN FLAP

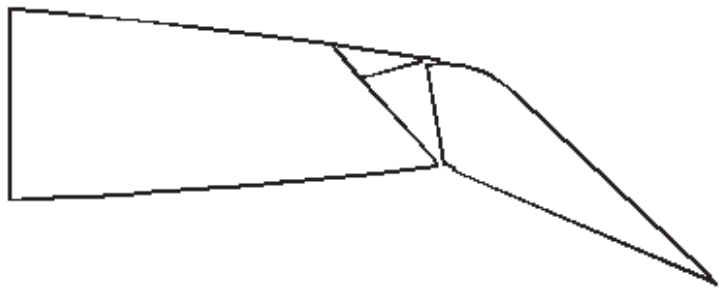

FOUND BUSH-HAWK FOWLER FLAP

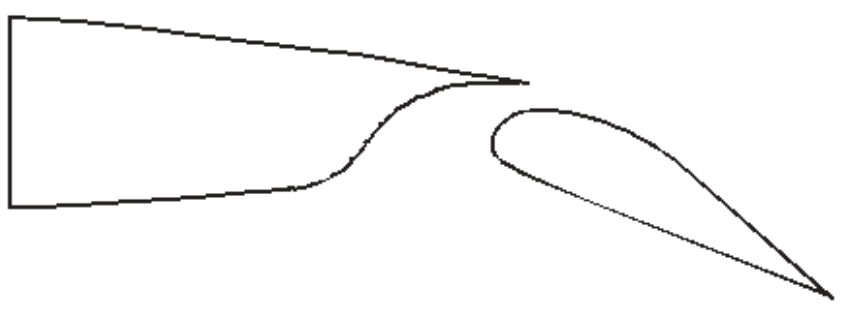

Figure 2. Bush Hawk plain flap and new slotted flap. 


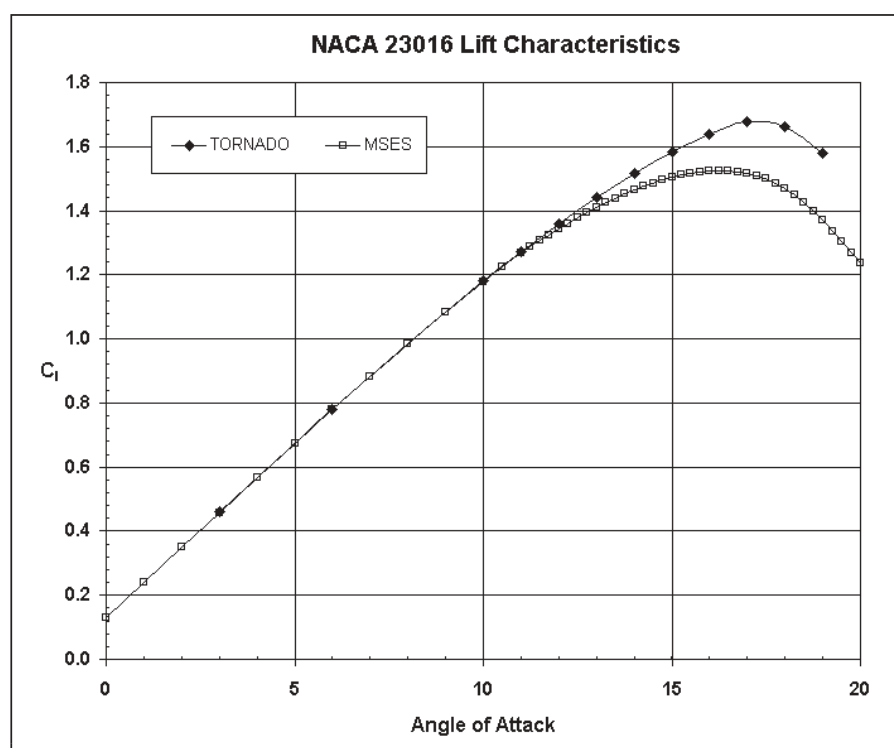

Figure 3. Lift curve estimates NACA 23016.

code predicted a higher stall angle and greater maximum lift coefficient than MSES, and this was also found later in cases with flaps deflected. For comparison, the NACA airfoil wind tunnel test data as given in Abbott and Von Doenhoff (1959) indicate a stall angle about $15^{\circ}$ and a $C_{\mathrm{Lmax}}$ about 1.5 , which are closer to the MSES estimates.

For practical reasons, when the flaps on the Bush Hawk XP are fully retracted, a significant slot remains at the shroud lip that allows flow leakage over the flap. This feature was recently investigated using the Tornado code, and it predicted that stall would be delayed by about $2^{\circ}$ while the maximum $C_{\mathrm{L}}$ was increased by about 0.2 relative to values for the basic airfoil.

The lift effectiveness of flaps can be compared using the increments obtained in $C_{\mathrm{Lmax}}$ relative to the basic airfoil that are achieved at various flap deflections. Such a comparison is summarized in Figure 4. Estimates are included for the original plain flap from MSES and for the new slotted flap using both MSES and the Tornado codes. Also for comparison, estimates were made for a Cessna Skyhawk airfoil and flap that were based on the measured geometry from an aircraft.

The new slotted flap is predicted to increase section maximum lift coefficients by about twice the increments obtained from the plain flap, across the entire range of flap angles. The predicted Skyhawk values are intermediate between these two results. The Tornado code was again found to predict larger increases in both maximum lift and stall angle than estimates given by MSES.

Typical chordwise pressure distributions predicted about the airfoil and flap, obtained using Tornado at a nominal flap deflection of $27^{\circ}$, are shown in Figure 5. Some trailing edge flow separation is evident on the flap upper surface throughout the incidence range shown; however, the shroud of the main airfoil does not begin to separate even at the highest incidence of $15^{\circ}$. The predicted stall angle from Tornado is about $19^{\circ}$, but

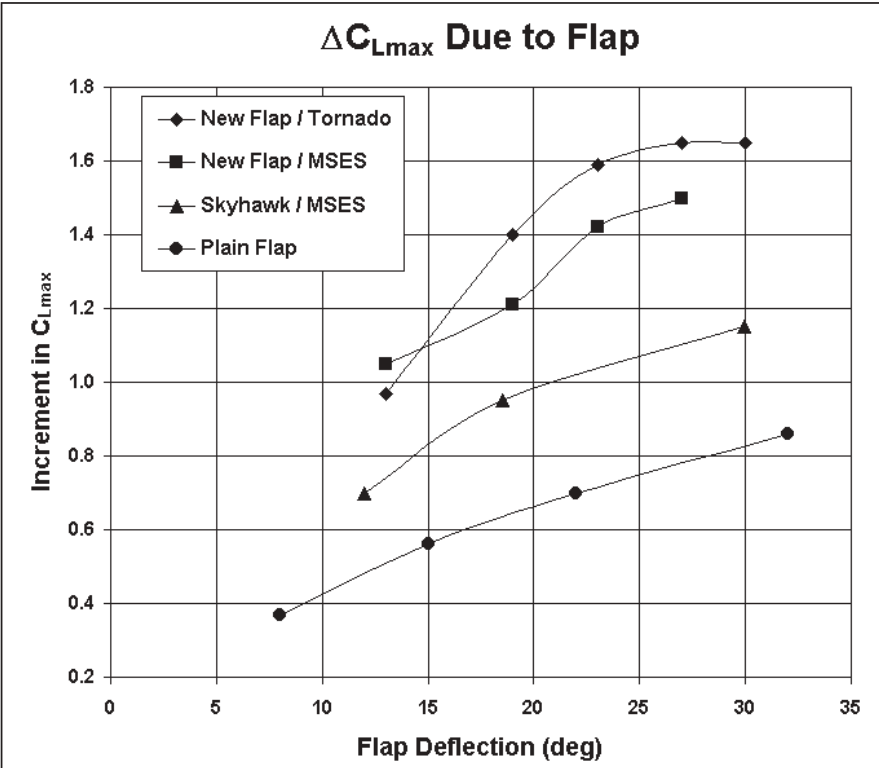

Figure 4. Increase in 2-D $C_{\mathrm{Lmax}}$ due to flap deflection.

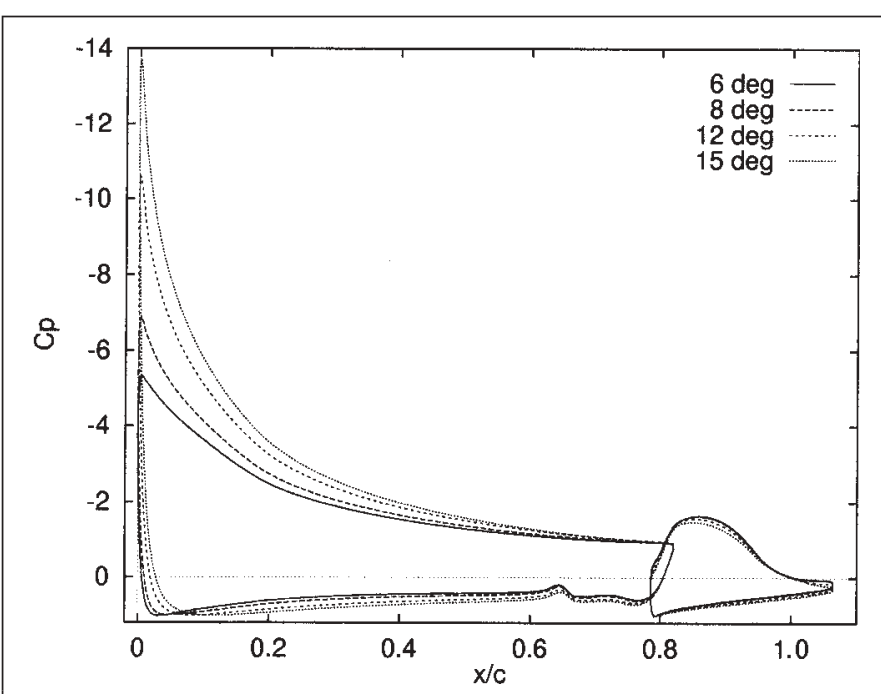

Figure 5. Chordwise pressure distributions on airfoil and flap at $27^{\circ}$ deflection.

the real airfoil with practical construction tolerances is unlikely to achieve such high values.

Flight tests were conducted with an alpha vane mounted on a long test boom on the outer wing; they showed the aircraft stalls at about $28^{\circ}$ of incidence with the landing flaps and idle power. From inviscid calculations made using the CMARC 3-D panel code (Aerologic Inc., 2000), this would correspond with a local 2 -D section incidence of about $16^{\circ}$ at the mid-flap station. This incidence is about $3^{\circ}$ less than the predicted section stall value from Tornado, so the high aircraft stall angles achieved are not untoward. 


\section{Structural Design and Drive System}

The design airloads on the flap were based on the FAR 23 Loads computer program given in McMaster (1988). This bases the flap lift component on a linearized potential flow analysis from Abbott and Von Doenhoff (1959, Figure 98) and obtains the chordwise load distributions from FAR 23 (FAA, Appendix A, Table 2). These methods are conservative, and adapting the available 2-D CFD results with viscous effects to predict the flap loads would have been preferable. However, Found had no proven reliable methods available at the time to make spanwise corrections to the 2-D flap loads. Since then Found began modelling the aircraft using the CMARC 3-D panel code of Aerologic Inc. (2000). The pressure distributions about a complete aircraft model with landing flaps is shown in Figure 6. Current work includes studies of 3-D effects on the flap loads obtained from CMARC to see if some loads relief can be achieved.

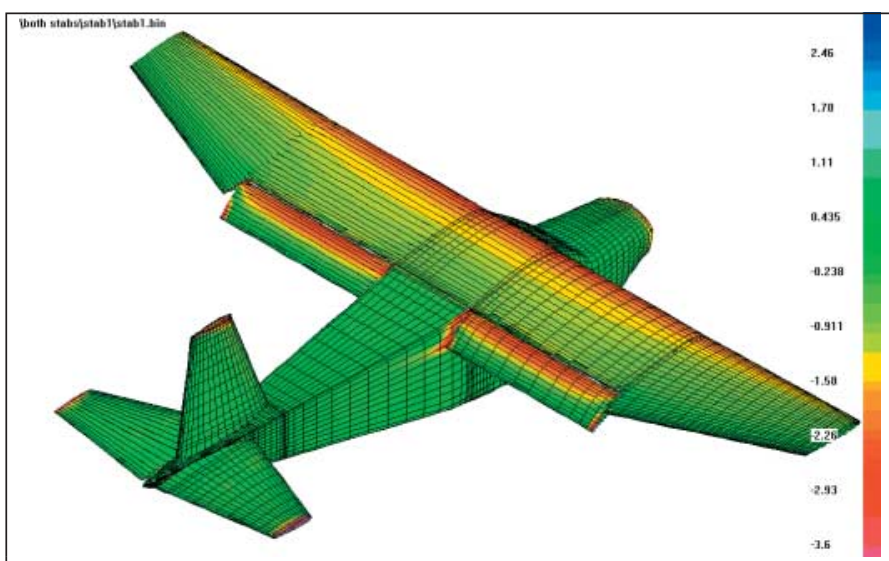

Figure 6. CMARC panel model of Bush Hawk XP.

Also in regards to flap design loads, during the flight test program a flap pushrod was instrumented on the test aircraft to measure loads in flight. This provides an indirect measure of the flap lift and the centre of pressure. The data gathered will enable comparisons to be made among the FAR 23 load estimates, the loads from applying the UTIAS 2-D section data across the flap span, and the loads from the CMARC panel method.

A layout illustrating the features of the flap extension and support arrangement is given in Figure 7. A track system was adopted rather than using external hinges because tracks could be fully enclosed within the airfoil profile. This also resolves operators' concerns over long hinges projecting below the wing and the possible injury to personnel during docking of floatplane versions. The buried track arrangement will also serve to reduce aircraft drag at cruise. Half hard stainless steel plates are used for the flap tracks, and the dimensions were based on limiting the peak roller contact stresses on the tracks. The ideal track shape was approximated using straight lines for the slots with only small deviations resulting in the flap locations.

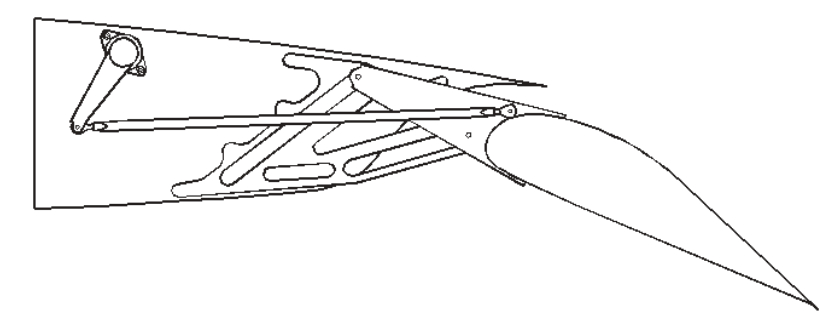

Figure 7. New flap support structure.

Details of the flap supports and drive system are shown in Figure 8. Each flap is carried at two spanwise stations inset from the ends. At each station there are two rollers carried on arms projecting ahead of the flap. These run in the track plates that are attached to strengthened ribs used to distribute the flap loads into the wing box. Each flap is extended by a single pushrod attached at the flap mid point and driven by an arm on a spanwise torque tube, see also Figure 7. The flap drive uses a single, irreversible, electrically driven actuator that rotates the torque tube.

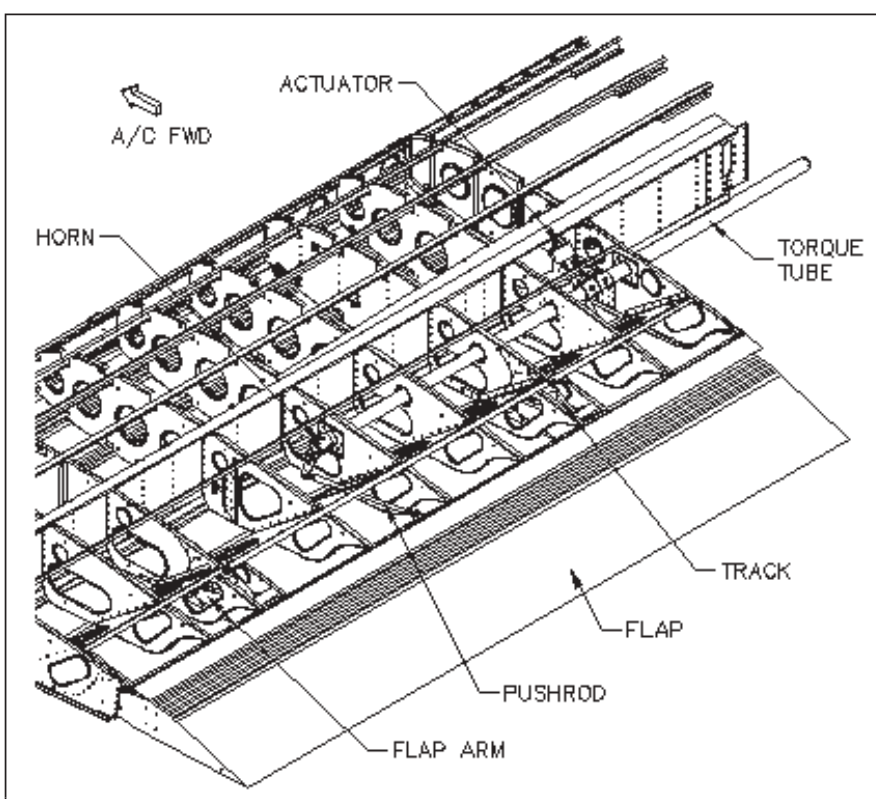

Figure 8. Flap drive system.

One side of the flap system was structurally tested to ultimate conditions when mounted from a shortened box representing the aft part of the wing, as shown in Figure 9.

There was concern over unusual flap torsion loads and lateral deflections resulting from possible flap jamming on one side due to debris or some other obstruction. Accordingly, tests were conducted in the ground test rig with a flap jam simulated. At limit loads the lateral deflections were low and there were no resulting permanent deformations of any structure or drive component. Such tests are beyond the applicable certification requirements for this category of aircraft and they were done to demonstrate additional safety. 


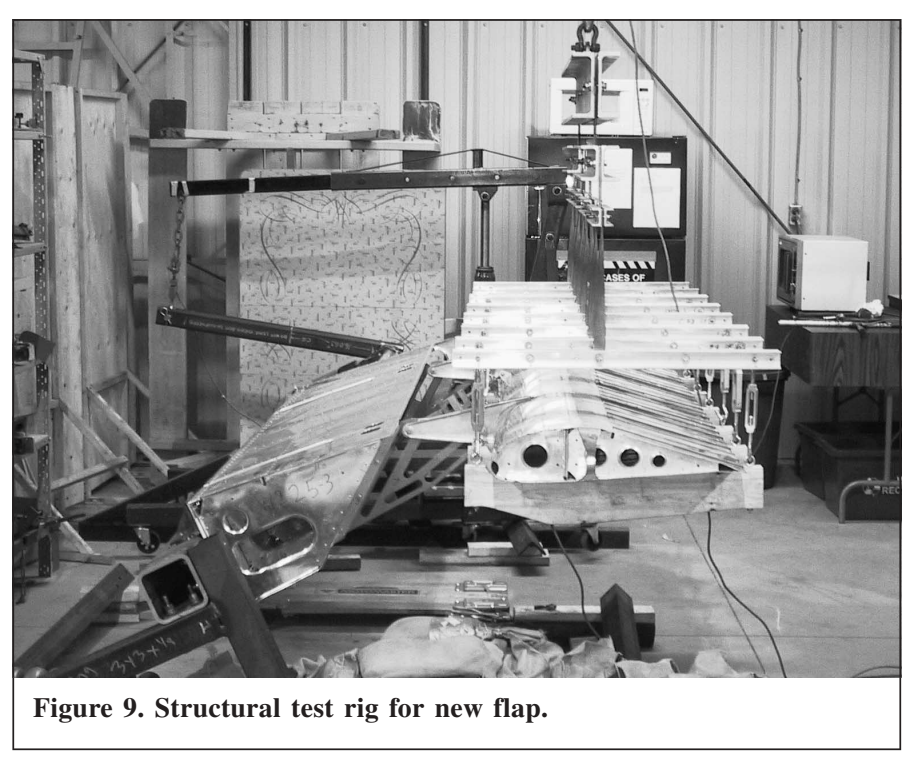

The flap actuator was sized to a higher capacity than needed for flight loads. Accordingly precautions were taken to limit the drive system loads in the event of the flap binding in the tracks or overrunning the stop switches and bottoming. The final design simply uses a load resistor placed in series with the drive motor to limit the peak current draw to acceptable levels and there is also a circuit breaker for backup. A series of ground tests was needed to iterate and find the required values for the load resistor. Later, flight tests were performed to demonstrate acceptable shut down behaviour.

A failure in the flap drive system is considered a very remote possibility, as the component stress levels were kept very low throughout. However, if a flap pushrod or connector on one side did fail, it would cause that flap to retract completely and impart large aerodynamic rolling moments. Rather than attempt a complex fail safe design to cover such an event it was decided to wait until test flights to see if the available aileron roll power was sufficient to contain the full flap asymmetry.

The original Bush Hawk flaps were hand operated via a long lever that rotated the torque tube for extending the flaps. This capability was retained on the test aircraft, as it enabled several special tests to be done in flight, particularly those to clear the flap and drive systems for failure cases. It also conveniently allowed the flap drive system to be cleared to limit loads on the ground before the first flight.

\section{Flight Tests}

\section{Stalls}

The first part of the flight test program to meet FAR 23 requirements was concerned with the stall handling characteristics of the aircraft and measurement of the maximum lift coefficients achieved. The flight testing followed the procedures given in the guide of the FAA (1989) for FAR 23 aircraft.

The stall behaviour in straight and turning flight was found quite benign with good natural stall warning and no undue tendency to drop a wing. As a result, neither stall fences nor leading edge droop were required to be fitted on the wing.

\section{Maximum Lift}

The maximum lift coefficients derived from the minimum stall speeds are listed in Table 1, which compares values for the new slotted flap with recent tests on the new plain flap version. All the values shown are for the most forward centre of gravity (CG) condition at flight idle power. Values are also included for the similar-sized Cessna $206 \mathrm{H}$ aircraft. At landing flap deflection the new slotted flap increases aircraft maximum lift coefficients about $34 \%$ above the original plain flap.

Table 1 also shows that the maximum lift coefficients obtained for the Bush Hawk XP are now higher than the Cessna $206 \mathrm{H}$ values; this is important for achieving superior airfield performance.

The maximum lift performance of the aircraft version with plain flaps was surprisingly poor, considering that the 2-D estimates had indicated significant increments in maximum lift were to be expected, see Figure 4. No tuft tests were done for verification, but it is conjectured that the squared-off corners of the fuselage and the absence of a wing-body fairing precipitated extensive flow separation and lift loss at the inboard ends of the plain flap.

With the flaps retracted the XP with its slotted flap shows a significant improvement in aircraft $C_{\mathrm{Lmax}}$ of about $16 \%$ over the plain flap version, as residual leakage through the slots energizes the flow over the flaps. The improvement achieved by the aircraft is even greater than the 2-D estimates from CFD, which showed the section maximum $C_{\mathrm{L}}$ increased by about 0.2 . This suggests the flap leakage may also help clean up the flow at the wing-body junction and gain further increased lift.

\section{Spins}

The aircraft flight test program also included spin testing, and recoveries from single-turn spins were demonstrated without any difficulties. No spin chute was fitted based on prior favourable experience, but for safety the crew entry doors were fitted with rip hinges and the pilot had a parachute. In all, 21 individual spins were done to cover a matrix of conditions of flap, CG location, engine power, and control actions at entry and during the recovery. Later, spin tests were made with floats on the aircraft and again the spin recovery was found to be satisfactory.

\section{Flap Asymmetry Tests}

To demonstrate safety if a flap retracted completely on one side because of a failure, the aircraft was flown in steady level flight under power with one flap fully retracted and one fully extended. The aircraft demonstrated safe controllable flight down to a speed of 50 knots IAS, which was below the full flap, power-off stall speed. These tests showed additional safety beyond that required by FAR23 and demonstrated that a fail safe flap drive system was not needed. 
Table 1. Aircraft maximum lift coefficients.

\begin{tabular}{|c|c|c|c|c|c|c|}
\hline & \multicolumn{2}{|c|}{ Bush Hawk plain flap } & \multicolumn{2}{|c|}{ Bush Hawk XP slotted flap } & \multicolumn{2}{|c|}{ Cessna $206 \mathrm{H}$ slotted flap } \\
\hline & $\delta F$ & $C_{\mathrm{Lmax}}$ & $\delta F$ & $C_{\mathrm{Lmax}}$ & $\delta F$ & $C_{\mathrm{Lmax}}$ \\
\hline \multirow[t]{3}{*}{ Takeoff } & 0 & 1.46 & 0 & 1.69 & 0 & 1.35 \\
\hline & 8 & 1.51 & 10 & 1.86 & - & - \\
\hline & 22 & 1.61 & 20 & 2.03 & 20 & 1.69 \\
\hline Landing & 32 & 1.61 & 30 & 2.16 & 30 & 1.87 \\
\hline
\end{tabular}

Table 2. Aircraft performance comparison.

\begin{tabular}{|c|c|c|c|}
\hline & $\begin{array}{l}\text { Bush Hawk } \\
\text { plain flap }\end{array}$ & $\begin{array}{l}\text { Bush Hawk } \\
\text { slotted flap }\end{array}$ & $\begin{array}{l}\text { Cessna } 206 \mathrm{H} \\
\text { slotted flap }\end{array}$ \\
\hline Maximum takeoff weight (lb) & 3200 & 3500 & 3600 \\
\hline Engine horsepower (hp) & 260 & 300 & 300 \\
\hline Empty weight (lb) & 1750 & 1900 & 2210 \\
\hline Takeoff to $50 \mathrm{ft}$ height at sea level ISA $(\mathrm{ft})(1 \mathrm{ft}=0.3048 \mathrm{~m})$ & 1785 & 1566 & 1860 \\
\hline Landing from $50 \mathrm{ft}$ at sea level $(\mathrm{ft})$ & 1455 & 1394 & 1395 \\
\hline Rate of climb flaps up at sea level (fpm) & 960 & 1009 & 989 \\
\hline Cruise speed at $75 \%$ power, $6000 \mathrm{ft}(\mathrm{kn})$ & 132 & 150 & 142 \\
\hline
\end{tabular}

\section{Performance}

The airfield and climb performance of the aircraft were determined when operating to FAR 23 requirements, for use in the aircraft flight manual (AFM). A special flight test instrumentation package, which is described in a paper by Eggleston et al. (2002), was used for these tests.

The performance of the new production version of the Bush Hawk with plain flaps, the XP with its slotted flaps, and the similar sized Cessna 206H are compared in Table 2. The table shows that the airfield distances required and the climb performance of the Bush Hawk XP are now superior to the plain flap version despite an increase of $10 \%$ in the maximum weight.

The significant increase in cruise speed shown for the XP version was the result of a drag clean up exercise taken in conjunction with the flap changes and the power increase.

\section{Conclusions}

This paper has described the development of a new, singleslotted flap system for Found Aircraft's Bush Hawk XP, which is a small utility transport aircraft. From this work it is concluded that

(1) modern CFD methods for 2-D airfoils and flaps are now sufficiently mature that they can dramatically reduce the time, cost, and risks incurred when developing new high lift systems

(2) to fully exploit the benefits of CFD in the future, Found Aircraft will need reliable, calibrated 3-D methods to replace the methods of the FAR 23 Loads program used to date for the flap loads

(3) the replacement of the earlier plain hinged, sealed flap with a new, CFD designed single-slotted flap enabled the aircraft maximum lift coefficients to be increased at all deflections and by about $34 \%$ for landing

(4) the new flap and increased engine power have enabled the $\mathrm{XP}$ to achieve the goal of having airfield and climb performance superior to the previous lighter weight versions and also other similar-sized aircraft in its class

\section{REFERENCES}

Abbott, I.H., and Von Doenhoff, A.E. (1959). "Theory of Wing Sections", Dover Publications Inc., New York, New York.

Aerologic Inc. (2000). "Digital Wind Tunnel Version 2.2 and CMARC Version 3.6. Three Dimensional Low Order Panel Codes". Aerologic Inc.,.

Drela, M., and Giles, M.B. (1987). "ISES: A Two Dimensional Viscous Aerodynamic Design and Analysis Code". AIAA Paper No. 87-0424.

Eggleston, B., McKinney, W.D., Choi, N.S., and Min, D. (2002). "A Low Cost Flight Test Instrumentation Package for Light Airplanes". Proceedings of the ICAS 2002 Congress, Toronto, Ontario. September 2002. Paper No. 6.6.2.

FAA. (). "Federal Aviation Regulation FAR Part 23 Airworthiness Standards: Normal, Utility, Acrobatic, and Commuter Category Airplanes". U.S. Federal Aviation Administration, Washington, D.C.

FAA. (1989). "Flight Test Guide for Certification of Part 23 Airplanes". Advisory Circular No. 23-8A. U.S. Federal Aviation Administration, Washington, D.C.

Godin, P., Zingg, D.W., and Nelson, T.E. (1997). "High Lift Aerodynamic Computations With One and Two-Equation Turbulence Models". AIAA J. Vol. 35, No. 9, pp. 237-243.

McMaster, H.C. (1988). "FAR23 Loads", Self Published.

Nelson, T.E., Zingg, D.W., and Johnston, G.W. (1993). "Compressible Navier-Stokes Computations of Multielement Airfoil Flows Using Multiblock Grids". AIAA J. Vol. 32, No. 3, pp. 506-511. 